\title{
Cheiloscopy, Palatoscopy and Odontometrics in Sex Prediction and Dis- crimination - a Comparative Study
}

\author{
Nagalaxmi V., Sridevi Ugrappa ${ }^{1}$, Naga Jyothi M. ${ }^{1,}$, Lalitha Ch. ${ }^{1}$, Kotya Naik Maloth ${ }^{2}$ and Srikanth \\ Kodangal $^{1}$ \\ ${ }^{1}$ Sri Sai College Of Dental Surgery, Vikarabad, Telangana, India \\ ${ }^{2}$ Mamata Dental College. Khammam, Telangana, India
}

\begin{abstract}
Background and Objectives: Human identification is the forensic odontologist's primary duty in the fields like violent crime, child abuse, elder abuse, missing persons and mass disaster scenarios. In each context, dental traits may produce compelling evidence to aid victim identity, suspect identity and narrow down the outcome of investigative casework. Sometimes it becomes necessary to apply some least known and less popular techniques in identification procedure where lip prints, rugae patterns and canine odontometrics can give us comparatively valid conclusions pertaining to person's identification. This study elucidates the significance of cheiloscopy, palatoscopy and canine odontometry in sex prediction and discrimination.
\end{abstract}

Materials and Methods: A cross- sectional study involving a total of 60 subjects, 30 males and 30 females were selected from the outpatient department of oral medicine and radiology. Lip prints were recorded using lipstick, palatal impressions were taken with alginate and odontometric measurements were taken with digital vernier calipers from every subject. All the obtained records were analyzed by two observers.

Results: Reliability of lip prints was assessed using Kappa coefficient. Comparison of rugae patterns was done using Chisquare test. Mean canine and inter canine width was compared using t test. A p-value of $<0.05$ was considered significant. Statistically significant difference was found with the different lip print patterns analyzed in males and females, while no significant difference was observed in the rugae patterns but a significant difference in the mesio-distal width of mandibular canines in males and females was found with right mandibular canine(3.73\%) showing greater sexual dimorphism compared to left mandibular canine(3.06\%).

Conclusion: This study shows the uniqueness of the lip prints and rugae patterns with the lip prints showing sensitivity of $81.7 \%$ giving reliable prediction of sex over palatoscopy. Hence, cheiloscopy along with the canine odontometrics aid in sex determination and can be considered as an ancilliary forensic tool in identification.

Keywords: Forensic identification, lip prints, mandibular canine index, rugae patterns, sex discrimination.

\section{INTRODUCTION}

Establishing the human identity using skeletal and dental traits provides a comprehensive data and compelling evidence that holds a paramount importance in the routine forensic investigations, Law enforcement agencies, Judicial system, mass disasters, palaeoanthropology. Though human beings belong to same species, the genetic determinants encode the distinctive characteristics of every individual facilitating the identification possible.

Forensic dentistry is a specialized branch of forensic medicine and may be described as that part of odontology which, in the interests of justice, deals with the handling and

*Address correspondence to this author at the Q.NO. B-4/59, NTPC, Ramagundam, Telangana (505215); India; Tel: 91-8019138210;

E-mail: 97jyothi@gmail.com examination of dental evidence, from which a proper evaluation and presentation of dental findings can be made. (Cameron and Sims, 1974 and Keiser-Nielson, 1980).

No two individuals in the world look alike and are unique and this concept of uniqueness is utilized in the human identification procedures. Although DNA profiling, finger prints, anthropometric data, dental records can be used as standard methods, sometimes it becomes obvious to employ some of the least and unusually used ancilliary methods like cheiloscopy, palatoscopy and other odontometric measurements that are capable of giving comparatively reliable results when performed systematically [1]. Gender discrimination is the important aspect of the human identification procedures that help in the establishment of biological profile from the skeletal and dental remains and also help in the facial reconstruction of unidentified bodies. 
Age, race, sex and stature determination along with dental evidence collection and facial reconstruction over the skeletal remnants are the important specialities of the forensic dentistry [2].

Latent imprints recorded on the smooth surfaces in the crime scene area requires evidence based comparative analysis for the identification of suspect as well as victim in the field of criminology [3-5]. These imprints are derived from the sources like fingers, palms, foot including the lips with its characteristic grooves and furrows although lip prints have not been as popular as others.

Similarly the patterns of palatine rugae exhibit racial and gender variations where they are not subjected to gross changes except in the length during the person's growth. They are protected from trauma and other extreme conditions like high temperatures as they are shielded by the lips, cheeks, tongue, teeth and bone and retain the same position and shape throughout the person's life once formed $[1,6]$. They also serve as a valuable tool in the conditions where finger prints or lip prints cannot be recorded like decomposed or burnt bodies. Its importance is justified by using it in the identification of pilots in aeronautical accidents with the aid of antemortem data [1].

Likewise the odontometric parameters also show ethnic, racial, and individual and to some extent geographic variations and they are least susceptible to the catastrophic changes and help in collecting the appropriate dental evidence. Teeth unlike soft tissues with their physiologic variations, pathoses and the ability to withstand extreme conditions of post mortem changes like decomposition, carbonization and fragmentation, are capable of providing information that remains throughout the life and beyond. Canines display sexual dimorphism and serve as a supplemental forensic tool in sex determination. They last long in the oral cavity as they are least prone to caries or periodontal disease and also withstand vulnerable conditions $[7,8]$.

Odontometrics is the measurement and study of tooth size used in biological anthropology, bioarchaeology to study human phenotypic variations. The present study is aimed at envisaging the application of the ancilliary methods in identification and sex discrimination - cheiloscopy, palatoscopy and mandibular canine index. This study also shows the inter and intra observer variability in the evaluation of these parameters.

\section{MATERIALS AND METHODS}

A total of 60 subjects, 30 males and 30 females were selected from the out-patient department of oral medicine and radiology attending the hospital for routine dental check up after acquiring the informed consent with the age groups ranging between 20-30 years. All subjects are absolutely normal with no evidence of congenital anomalies, soft tissue surgeries, trauma, orthodontic treatment, orthognathic surgeries, malocclusions, attrition and other regressive alterations of teeth, caries free teeth, normal molar and canine relationship. From every subject, the lip prints, palatal impressions and odontometric measurements were recorded on the same day.

\section{LIP PRINTS}

The materials used for recording the lip print are:

1. Lipstick - of a bright red colour and non-glossy, Revlon Red (number 64), REVLON, made by Aero Pharma Pvt Ltd, Mumbai was used.

2. Cellophane tape that was transparent and glued on one side of $24 \mathrm{~mm}$ width (Hi- TECH). This is sufficient to take the print of one lip at a time.

3. Deep pore cleanser

4. Scissors.

5. A4 size white bond paper (JK excel bond).

6. Tissue paper.

7. Gauze with saline to remove the lipstick.

The upper surface of the lipstick was wiped clean on tissue paper prior to each use for hygienic purpose. The subject was asked to open the mouth and lipstick applied in a single stroke evenly on the upper lip followed by the lower lip. The subject was asked to rub his or her upper and lower lips together gently to ensure even application of the lipstick throughout the lips. A strip of cellophane tape, 1 inch long was cut out with scissors. The subject was asked to open the mouth slightly, and to keep the mouth stationary during the procedure. The glued portion of the cellophane tape was then applied on the lower lip and held in place, applying gentle and even pressure for a few seconds, to allow the print to form on the tape. Then the tape was carefully lifted from the lip, from one end of the strip to the other, in a single jerk avoiding any smudging of the print. The strip of cellophane tape was then stuck on to a piece of white bond paper for further analysis by using magnifying lens. Each lip print was coded without revealing the name and sex of the subject to the observers (Fig. 1).

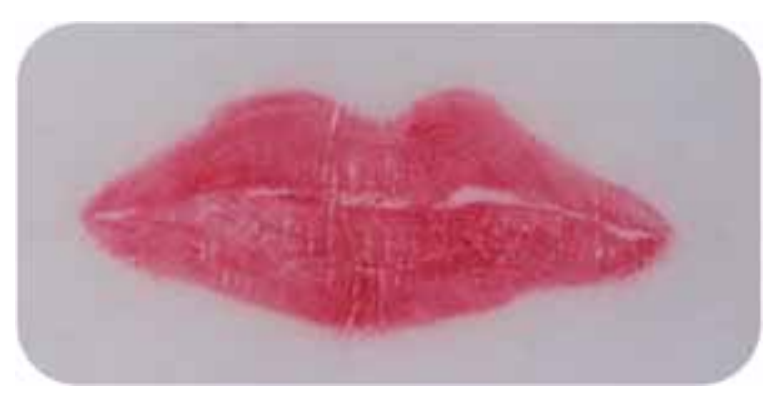

Fig. (1). Lip print of a female subject.

\section{ANALYSIS OF LIPPRINTS}

Topographically, each lip print was divided into 6 areas such that each lip have 3 zones. Right upper lateral, upper middle, left upper lateral, left lower lateral, lower middle and right lower lateral zones as in (Fig. 2). The most predominant and clearly visible patterns in each zone are considered in sex determinations which were later verified from the actual details of the subjects for drawing conclusions. In our study we followed the classification of the lip-patterns sug- 


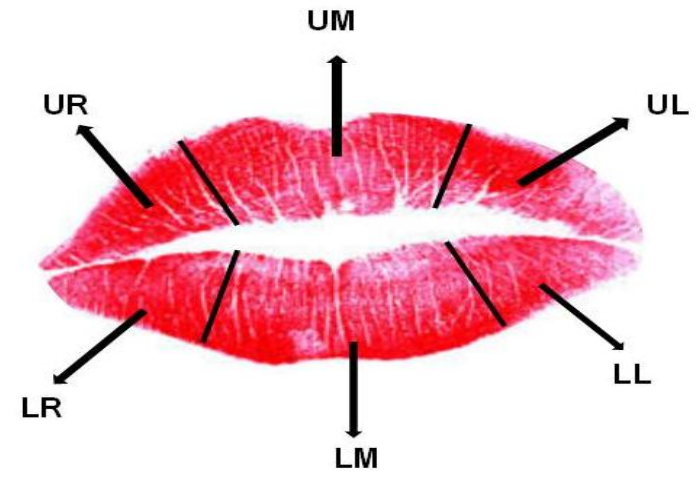

Fig. (2). Topographic division of lip into 6 zones for lip print pattern analysis.

gested by Suzuki and Tsuchihashi [9] giving the arrangement of grooves. $\operatorname{lip}$

Type 1-Clear-cut grooves running vertically across the

Type I' The grooves are straight vertical but discontinuous not running entirely across the lip. of $\mathrm{Y}$

Type II- The grooves branch in their course in the shape

Type III- Intersecting grooves

Type IV- Reticular pattern

Type V- The grooves do not fall into any of the types IIV, and cannot be differentiated morphologically and are irregular.

\section{ANALYSIS OF PALATAL RUGAE}

For palatal rugae, we recorded alginate impressions of the maxillary arch of the same subjects and models were poured in dental stone along with the plaster bases for further analysis. Care was taken to rule out any palatal swelling or other pathologies, denture wearers and subjects with full complement of teeth. Rugae were delineated with dark graphite lead black pencil as in (Fig. 3), under adequate day light and the patterns were analyzed by the observers using magnifying lens. The following criteria were considered in analyzing them which are as follows:

1. Total number of rugae.

2. Primary rugae with length in its greatest dimension $\geq$ $5 \mathrm{~mm}$ were considered.

3. Secondary or fragmentary rugae with length $\leq 5 \mathrm{~mm}$ were not considered.

4. Predominant shape of the rugae.

5. Fusion and course of direction of the rugae from the mid-palatine raphe.

The analysis was done using modified Lysell [10] who proposed the following patterns based on the shape as follows:

1. Straight: They follow a straight or linear pattern from the origin to termination.

2. Curved: They depict a crescent shape with a slight bend either at the origin or termination or both of the rugae under consideration.

3. Wavy: Curved rugae with slight curve at the origin or termination in the wave form.

4. Circular: Rugae that form a definite circular ring.

5. Unification (diverging): Two rugae with common origin but separate terminations.

6. Unification(converging): Two rugae with separate origins but uniting at the termination laterally.

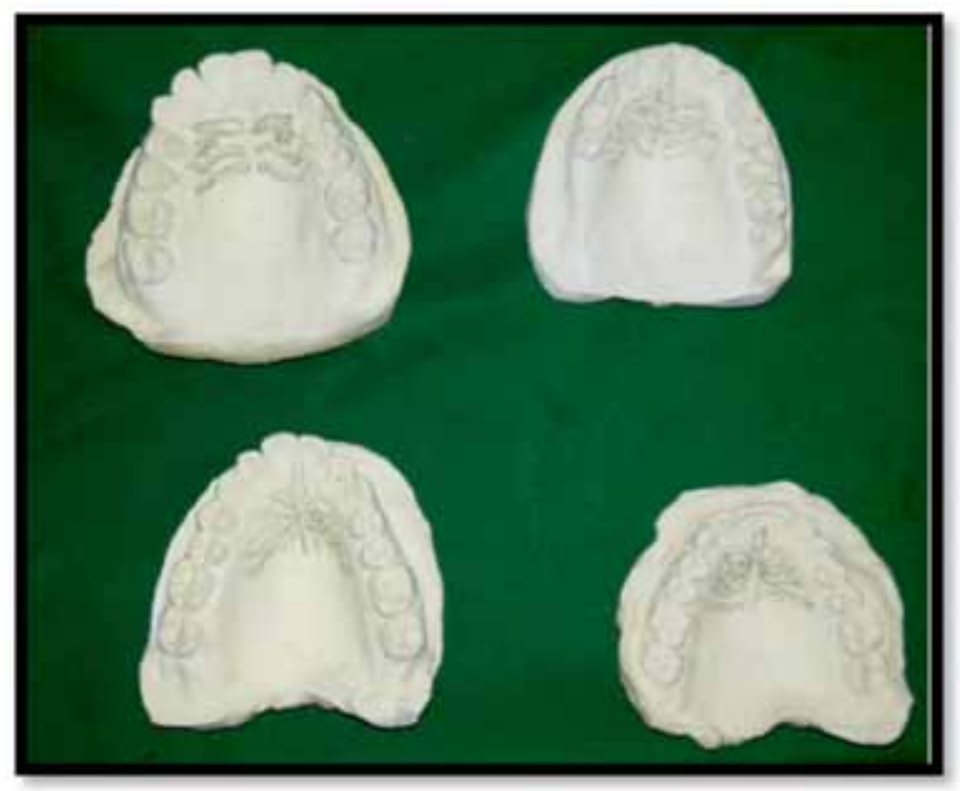

Fig. (3). Casts showing different palatal rugae patterns. 


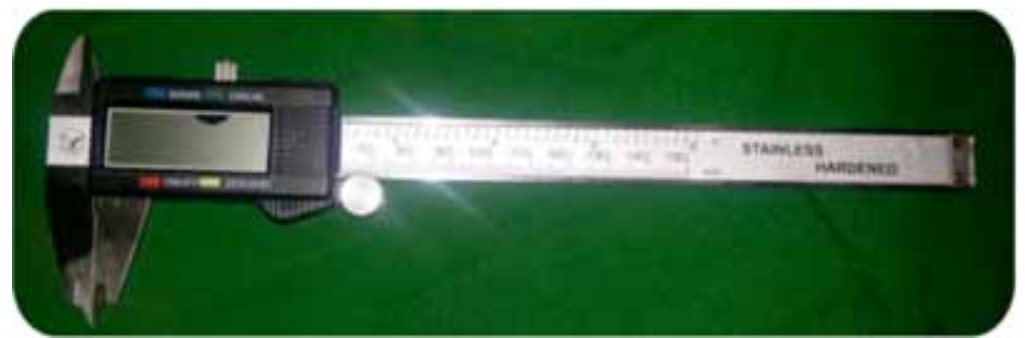

Fig. (4). Digital Vernier calipers device.

The corresponding patterns for each subject were coded as the numbers $1-6$ as mentioned above by the two observers who were blinded from each other.

Odontometric measurements were recorded intraorally using digital vernier calipers with a resolution of $0.02 \mathrm{~mm}$ from the informed consent and other indices were derived from the recorded values excluding the subjects with bruxism, morphological and pathological alterations of teeth (Fig. $4 \& 5)$.

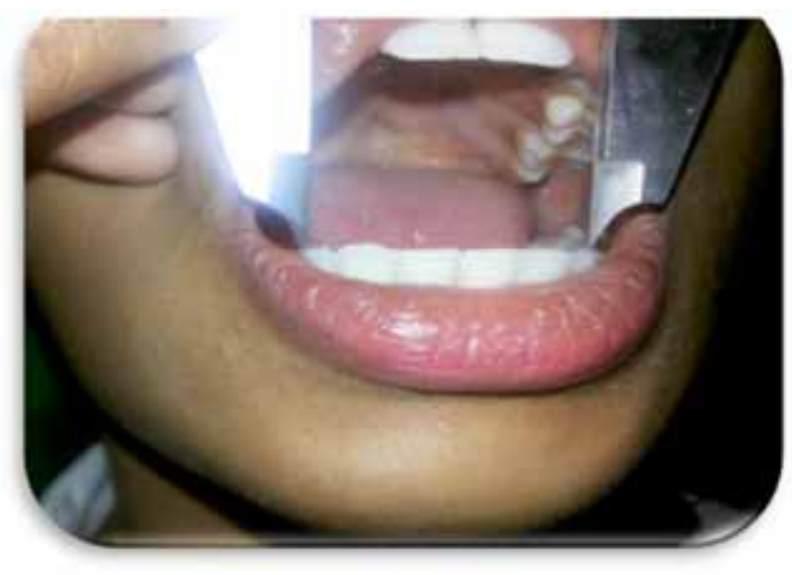

Fig. (5). Measurement of mesiodistal width of mandibular canine by clinical examination.

1. The mandibular canine width: The greatest mesiodistal width (MDW) between the mesial and distal contact points of the right and left mandibular canine.

2. The mandibular inter canine width (ICW) or arch width: was measured as the distance between the cusp tips of right and left mandibular canines.

Each parameter was repeated three times to get average measurements. Mandibular canine indices were calculated as per the formula used by Rao et al. [11] as

Mandibular canine index $($ MCI $)=\frac{\text { Mesio }- \text { distal width of right } \& \text { left lower canine }(\mathrm{MDW})}{\text { Mandibular inter canine width }(\mathrm{ICW})}$

All the values were tabulated in the standard Microsoft excel sheet and subjected to statistical analysis using " $\mathrm{t}$ " test.

Sexual dimorphism for both right and left mandibular canines was also calculated according to Garn and Lewis [12] as follows:

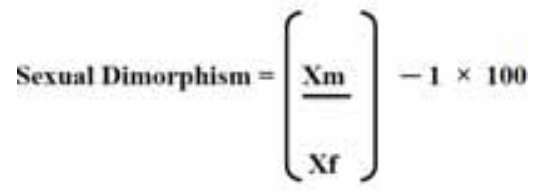

$(\mathbf{X m}=$ mean value of male canine width $; \mathbf{X f}=$ mean value of female canine width).

Standard Mandibular canine index (MCIs) value was obtained from the derived values for the comparative analysis using the formula as:

Standard MCI (MCIs) - [(Mean male MCI - SD) + (Mean female MCI + SD)]

\section{2}

\section{RESULTS}

All the analysis was done using SPSS version 14. A pvalue of $<0.05$ was considered significant. Reliability of lip prints to predict gender was assessed using Kappa coefficient (Fig. 6). Comparison of rugae patterns between male and females was done using Chi-square test. Mean canine and inter canine width was compared using $t$ test. The Objectives of this study include:

1. Identification of sex by means of cheiloscopy, rugoscopy and odontometric methods.

2. Evaluate the inter and intra-observer variability after studying the above three parameters.

3. To assess and compare the reliability of these parameters in identification of sex.

\section{Interpretation of Kappa}

\begin{tabular}{|c|c|c|c|c|c|c|}
\hline & Poor & Slight & Fair & Moderate & Substantial & Almost perfect \\
\hline 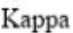 & 0.0 & .20 & .40 & .60 & .80 & 1.0 \\
\hline
\end{tabular}

$\begin{array}{ll}\frac{\text { Kappa }}{<0} & \text { Agreement } \\ 0.01-0.20 & \text { Sess than chance agreement } \\ 0.21-0.40 & \text { Fair agreement } \\ 0.41-0.60 & \text { Moderate agreement } \\ 0.61-0.80 & \text { Substantial agreement } \\ 0.81-0.99 & \text { Almost perfect agreement }\end{array}$

Fig. (6). Kappa measurement scale. 
Table 1. Kappa coefficient test for proportion to assess sex differences in lip print patterns.

\begin{tabular}{|c|c|c|c|c|c|}
\hline \multirow{2}{*}{} & \multicolumn{2}{|c|}{ Predicted Lip Gender } & \multirow{2}{*}{ Kappa } & \% Agreement \\
\cline { 2 - 5 } & Male & Female & \\
\hline \hline \multirow{2}{*}{ Actual gender } & Male & 28 & 2 & \multirow{2}{*}{0.633} & 81.67 \\
\cline { 2 - 4 } & Female & 9 & 21 & \\
\hline
\end{tabular}

Table 2. Inter and intra observer variability assessed by kappa co-efficient to assess sex differences in lip print patterns.

\begin{tabular}{|c|c|c|c|c|c|}
\hline & & \multicolumn{2}{|c|}{ 2nd Observer } & \multirow{2}{*}{ Kappa } & \multirow{2}{*}{$\%$ Agreement } \\
\hline & & Female & Male & & \\
\hline \multirow{2}{*}{ 1st observer } & Female & 20 & 9 & \multirow{2}{*}{0.465} & \multirow{2}{*}{73.33} \\
\hline & Male & 7 & 24 & & \\
\hline
\end{tabular}

\section{LIP PRINTS}

According to our study lip print analysis gave us the following observations.

No two lip prints showed similar patterns and distribution in each quadrant by both the observers. We observed more than two patterns in each individual and the distribution of these patterns in each quadrant we divided also showed variations from each other. Type I' pattern was dominant in predicted female gender with an overall contribution of $43.3 \%$ taken from both the observers with average readings followed by Type I with $10 \%$, Type II with $28.3 \%$, Type III sharing $11.6 \%$, Type IV with $3.3 \%$ and Type V with $6.6 \%$ respectively. In males Type III was dominant with $46.6 \%$ followed by Type IV with $26.6 \%$, Type V with $15 \%$, Type II with $8.3 \%$ and Type I' with $6.6 \%$ respectively. We also recorded the lip prints in 10 subjects after 3 months and compared the two patterns before and after 3 months to rule out any variations, but they remained to be same indicating their permanence once they are formed which don't change in the lifetime. We also observed the lip prints patterns in the same family in three subsequent generations in 5 subjects which showed similar pattern in the Upper and lower middle zone of the lips but showed variation in the distribution indicating its uniqueness in the same family. Two zones in each lip showed similar patterns in $46 \%$ of the individuals while other zones showed varied patterns hence showing the differences in distribution helping in identification. Total number of females correctly predicted was $81.7 \%$ and in males $88.4 \%$ were correctly predicted. The reliability of this method using kappa co-efficient showed minimal difference between actual and predicted gender with an agreement $81.67 \%$ indicating substantial agreement as in Table $\mathbf{1}$.

The inter and intra observer variability also assessed by kappa co-efficient showed $73.33 \%$ of agreement as in Table 2.

\section{PALATAL RUGAE}

We observed a total of 243 primary rugae in females and 238 primary rugae in males in the study which did not con- tribute to the statistical difference. The predominant shape of rugae in males was wavy followed by curved with straight pattern showing the least. The ring form was rare and we found in only one female subject. In females the predominant shape was also wavy and curved followed by the unification (diverging) pattern and straight pattern respectively as corroborated in Table 3 . No significant inter- observer variation was seen in the rugae shapes but variable rugae shapes were seen in males and females thus serving as an adjunct tool in sex discrimination. Applying the Chi-square test, we observed a $\mathrm{p}$ value of 0.785 which was non-significant as in Table $\mathbf{3}$ and the chart $\mathbf{1}$.

\section{CANINE INDEX}

Mean canine and inter canine width was compared using $\mathrm{t}$ test. The statistical derivations for all the odontometric measures were given in the Table 4 and chart $2 \& 3$.

The mean inter canine width showed higher value of $26.76 \pm 1.90$ in males in contrast to $25.77 \pm 1.66$ as in females with a p-value significant. Similarly, the mean mesio-distal widths of right and left mandibular canines also showed statistically significant difference whereas the right and left canine indices showed the p-value as non-significant. The overall assessment showed lower parametric values in females with respect to inter-canine width and mesio-distal widths of both the canines than in males. Similar observations in males and females has been observed by Kaushal et al. [13] (male: 25.873 \pm 1.253 , female: $25.070 \pm 1.197$ ), Reddy et al. [14] (male: 26.860 \pm 1.48 , female: 26.287 \pm 1.45 ),

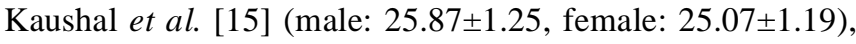
Abdullah et al. [16] (male: 26.9552 \pm 2.3129 female: $26.4575 \pm 2.7790)$.

Table 5 \& 6 shows percentage of sex correctly predicted using right and left side Mandibular Canine Index (MCIs) with the overall percentage of subjects correctly identified was found to be $61.7 \%$ using left canine (33) and $71.7 \%$ using right canine (43) respectively with the right mandibular canine as a reliable tool compared to left canine. The probability of sex determination using right MCI for males and 
Table 3. Chi square test for proportion to assess sex differences in palatal rugae patterns.

\begin{tabular}{|c|c|c|c|c|c|c|}
\hline & \multirow{3}{*}{ S.No. } & \multicolumn{4}{|c|}{ Actual Gender } & \multirow{3}{*}{ p-value } \\
\hline & & \multicolumn{2}{|c|}{ Male } & \multicolumn{2}{|c|}{ Female } & \\
\hline & & $\mathbf{N}$ & $\%$ & $\mathbf{N}$ & $\%$ & \\
\hline \multirow{6}{*}{ Rugae } & 1 & 2 & $6.7 \%$ & 1 & $3.3 \%$ & \multirow{6}{*}{0.785 ; NS } \\
\hline & 2 & 5 & $16.7 \%$ & 5 & $16.7 \%$ & \\
\hline & 3 & 17 & $56.7 \%$ & 19 & $63.3 \%$ & \\
\hline & 4 & 0 & $.0 \%$ & 1 & $3.3 \%$ & \\
\hline & 5 & 3 & $10.0 \%$ & 3 & $10.0 \%$ & \\
\hline & 6 & 3 & $10.0 \%$ & 1 & $3.3 \%$ & \\
\hline
\end{tabular}

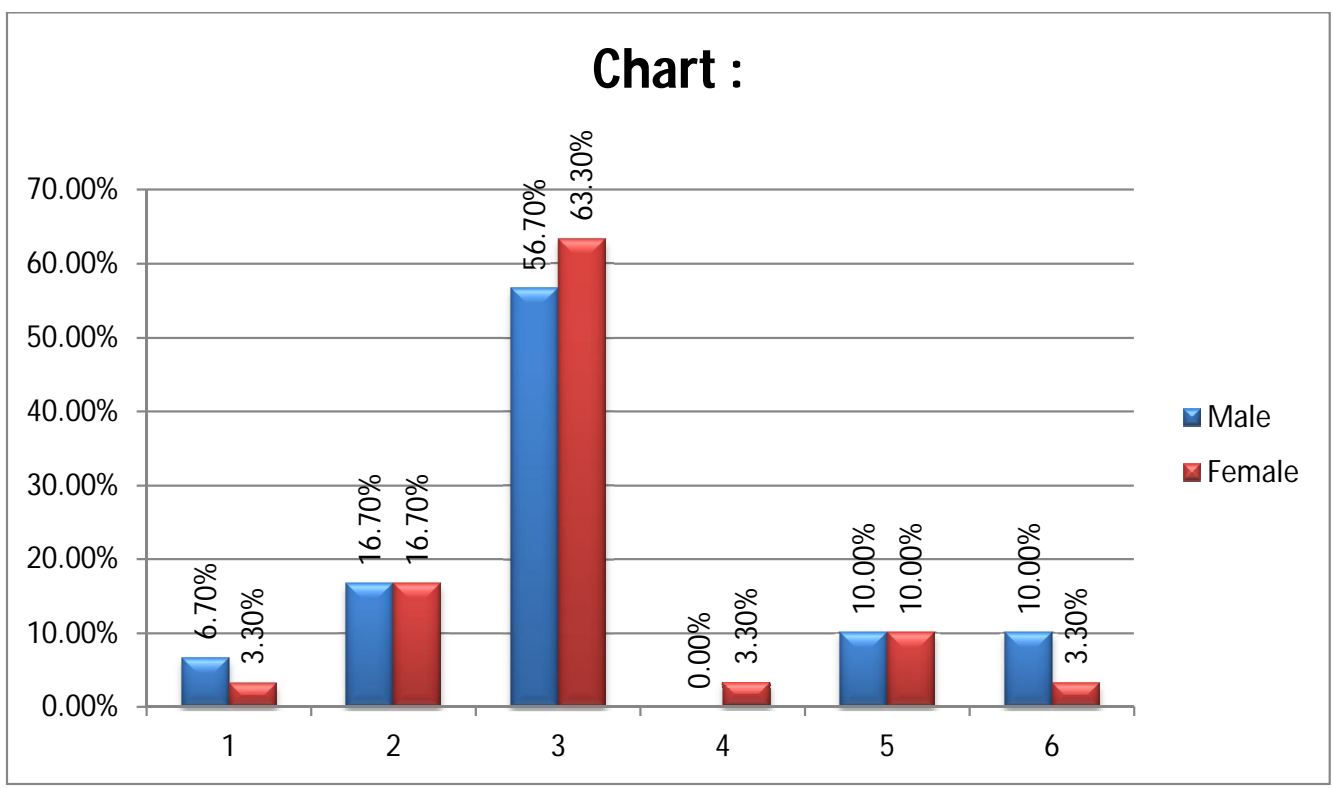

Chart 1. Graphical presentation of palatal rugae patterns in males and females.

Table 4. $t$ test for proportion to assess sex differences in mandibular canine odontometrics.

\begin{tabular}{|c|c|c|c|c|c|c|}
\hline & \multicolumn{4}{|c|}{ Actual Gender } & $\mathbf{t}$ & p-value \\
\hline MDW43 (right) & 6.66 & .37 & 6.42 & .28 & 2.866 & 0.066; Sig \\
\hline MDW33 (left) & 6.73 & .34 & 6.53 & .31 & 2.32 & $0.024 ;$ Sig \\
\hline MCI_right (43) & .2501 & .0213 & .2497 & .0128 & 0.073 & $0.942 ; \mathrm{NS}$ \\
\hline MCI_left (33) & .2524 & .0203 & .2540 & .0127 & -0.349 & $0.729 ; \mathrm{NS}$ \\
\hline
\end{tabular}

MDW $=$ Mesio-distal width $. \mathrm{MCI}=$ Mandibular canine index. $\mathrm{ICW}=$ Inter canine width 


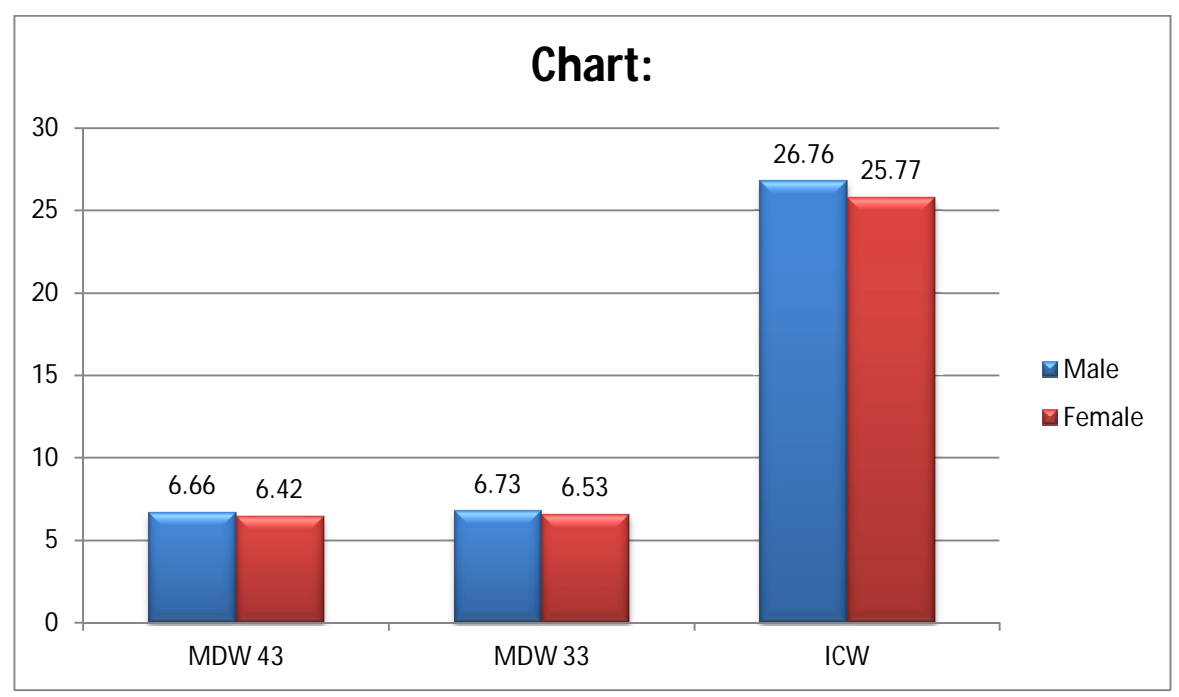

Chart 2. Graphical presentation of mandibular canine odontometric measurements.

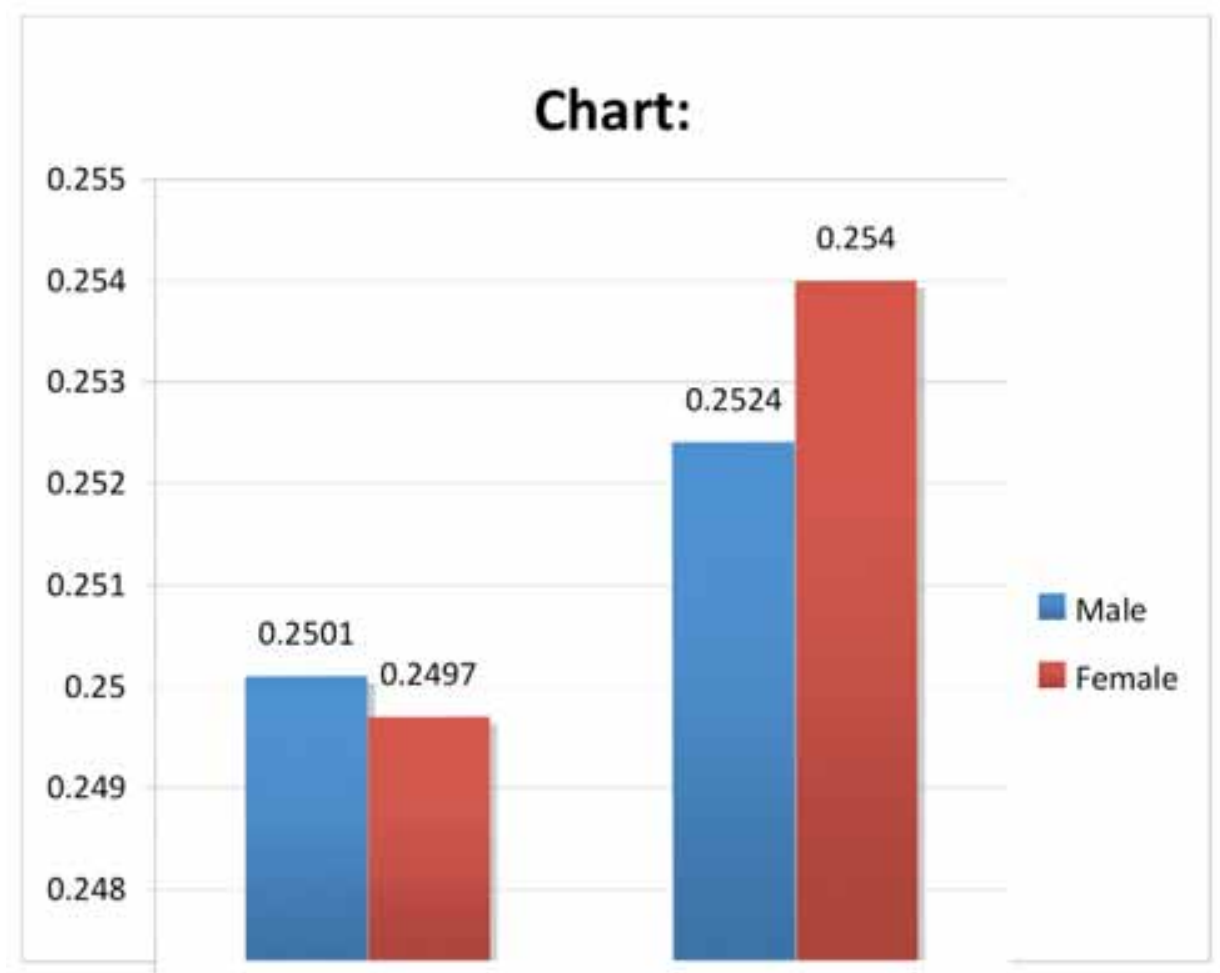

Chart 3. Graphical presentation of standard mandibular canine index in males and females.

Table 5. MCI 43 (Right canine): Percentage of sex correctly predicted using right Mandibular Canine Index (MCIs).

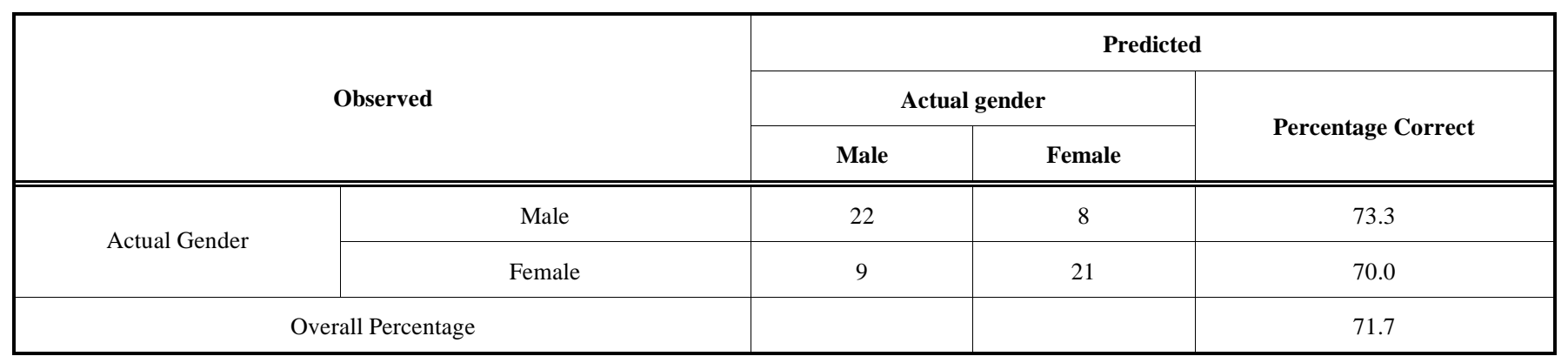


Table 6. MCI 33(left canine): Percentage of sex correctly predicted using left Mandibular Canine Index (MCIs).

\begin{tabular}{|c|c|c|c|c|}
\hline & & \multicolumn{3}{|c|}{ Predicted } \\
\hline \multirow{2}{*}{\multicolumn{2}{|c|}{ Observed }} & \multicolumn{2}{|c|}{ Actual gender } & \multirow{2}{*}{ Percentage Correct } \\
\hline & & Male & Female & \\
\hline \multirow{2}{*}{ Actual Gender } & Male & 20 & 10 & 66.7 \\
\hline & Female & 13 & 17 & 56.7 \\
\hline \multicolumn{2}{|c|}{ Overall Percentage } & & & 61.7 \\
\hline
\end{tabular}

Table 7. Assessment of sexual dimorphism in right and left mandibular canine.

\begin{tabular}{|c|c|c|c|c|c|}
\hline & \multicolumn{4}{|c|}{ Actual Gender } & \multirow{3}{*}{ Sexual dimorphism } \\
\hline & \multicolumn{2}{|c|}{ Male } & \multicolumn{2}{|c|}{ Female } & \\
\hline & Mean & SD & Mean & SD & \\
\hline MDW43 & 6.66 & .37 & 6.42 & .28 & $3.73 \%$ \\
\hline MDW33 & 6.73 & .34 & 6.53 & .31 & $3.06 \%$ \\
\hline
\end{tabular}

females was $73.3 \%$ and $70.0 \%$ and by using left MCI for males and females, it was $66.7 \%$ and $56.7 \%$ respectively. Further, the probability of correct prediction of sex using MCI is higher for females. We have noted an overall higher percentage of accuracy for sex prediction from right side MCI as compared to left side MCI.

It has been observed that the right mandibular canine exhibited greater sexual dimorphism $(3.73 \%)$ as compared to left canine $(3.06 \%)$ as in Table 7 . It has been further observed that whenever mesio-distal canine width was greater than $7.3 \mathrm{~mm}$, the probability of sex being male was ascertained but it must be substantiated and validated by large sample size. Our findings are different to those of other studies who have reported the left mandibular canine to exhibit greater percentage of dimorphism with still higher value of $7.954 \%, 9.058 \%$, and $8.891 \%$ respectively [13-15] influenced by ethnic and geographical variations.

A comparison of observed MCI with standard MCI has also been utilized for predicting sex of an individual. According to Rao et al. [11], if the calculated Mandibular Canine Index (observed MCI) for the individual is higher than the Standard Mandibular Canine Index (MCIs) the individual is considered to be male while if it is less than the standard MCI, the subject is considered to be female. In our study we obtained a standard MCI value as 0.246 with the help of which the overall accuracy of predictive value was found to be $61.6 \%$ in males and $33.3 \%$ in females.

\section{DISCUSSION}

The positive identification of the living or deceased individual is using various dental and skeletal traits owing to their unique features with variations and stability against external factors remains to be the important sources of forensic investigations. The most common role of the forensic dentist is the identification of deceased individuals [17].

Forensic dentistry represents the overlap between the dental and the legal professions which plays a major role in body identification. Human identification by dental and other allied orofacial structures beholds importance for various purposes like criminal, legal, mass causalities, aviation disasters, legal heirship, marital affairs, divorce, human trafficking, child abuse and similar other antisocial crimes [18]. Sometimes dental appliances like labeled dentures, orthodontic braces and other dental materials also provide clues to assist in the identification procedures. The traditional methods for personal identification include anthropometry, finger prints, sex determination, age estimation, measurement of height, and differentiation by blood groups, DNA and odontology [9]. Identification in forensic dentistry is a comprehensive procedure utilizing traditional, ancilliary tools and also taking the help of novel and accurate methods like DNA profiling. Because of the resistant nature of dental tissues to environmental assaults, such as incineration, immersion, trauma, mutilation and decomposition, teeth represent an excellent source of DNA material which aid in sex determination [19]. Teeth represent an excellent source of genomic and mitochondrial DNA obtained by cryogenic grinding. Inspite of all these advance methods of sex determination, the other ancilliary methods like cheiloscopy, palatoscopy and odontometry also gives reliable results in the face of being cost effective and easy to perform on the living as well as deceased [20].

Lip prints bring added evidence to a crime scene that can be valuable, especially in cases lacking other evidence like fingerprints, although the credibility of lip prints is still not established in the court system. The study of lip prints is known as cheiloscopy. Cheiloscopy (from the Greek words 
cheilos meaning "lips" and eskopein meaning "to see") is the name given to the lip-print studies. Like fingerprints and palatal rugae, the lip grooves are permanent and unchangeable. It is possible to identify the lip print patterns as early as the sixth week in intrauterine life. From that moment on, the lip groove patterns rarely change, resisting many afflictions and hence lip prints aid as a tool in human identification [21, 22].

Lip prints can be obtained at the crime scene from clothing, cups, glasses, cigarettes, windows and doors [22]. Even the invisible lip prints can be used and can be lifted using aluminum and magnetic powder similar to finger prints. Lip prints are invariable, permanent and allow establishing a classification. Lip print analysis in our study by both the observers showed the distinct patterns from each other where no two patterns were identical in compliance with other studies conducted by Tsuchihashi and Suzuki [9] and also other authors [23-25]. The biological phenomenon of systems of furrows on the red part of human lips was first noted by anthropologists, R. Fischer who was the first to describe it in 1902 [23]. Use of lip prints in personal identification and criminalization was first recommended in France by Edmond Locard [23]. Some researchers are trying to relate characteristic lip patterns with person's gender, and detected DNA in latent lip prints [25]. We found type I' pattern to be dominant in females and type III in males consistent with other studies [26-28]. However, Dongarwar et al. [29] in their study found type IV and type $\mathrm{V}$ patterns to be dominant in males and type I and type I' patterns to be dominant in females with slight deviation from our study.

Palatoscopy or palatal rugoscopy is the name given to the study of palatal rugae in order to establish a person's identity. Palatal rugoscopy was first proposed in 1932, by a Spanish investigator called Trobo Hermosa. Palatal rugae are irregular, asymmetric ridges of mucous membrane extending from the incisive papilla laterally and the anterior part of the median palatal raphe [30].

Palatal rugae are formed in the 3rd month in utero from the hard connective tissue covering the bone. The occurrence, number and arrangement of palatal rugae in mammals are species-specific. In humans they are asymmetrical, which is an exclusive feature of human beings [31,32]. As with lips, inter-racial differences in palatoscopy can also be established [33]. However, to reach definitive conclusions, more studies should be carried out. The most predominant pattern in our study was wavy, followed by curved pattern, which was in accordance with the other studies [34, 35]. The diverging pattern was equal in both the genders while the converging pattern was predominant in males whereas in the study by Divya et al. [36], diverging pattern was found to be dominant in females although the reliability and variability is needed to be evaluated on large sample size. The individualized pattern of palatal rugae and their low utilization costs make it a reliable guiding tool in forensic identification and its clinical importance can be found in the field of dentistry.

There are several ways to analyze palatal rugae. Intraoral inspection is the common method and others include oral photography and oral impressions [37]. Calcor rugoscopy or the overlay prints of palatal rugae in a maxillary cast, stereoscopy method giving three dimensional image of palatal rugae anatomy. However, due to its simplicity, price and reliability, the study of maxillary dental casts is the most used technique. From our study we could establish that rugae patterns showed distinctive patterns but no specific characteristic pattern was observed in either sex with much significant difference. However palatal rugae still holds a unique feature of an individual aiding in the forensic dentistry. Its importance can be validated on the large sample of population.

Apart from skeletal domain, dental hard tissue domain involving odontometric analysis of the teeth also helps in identification of sex. The study of teeth holds importance in anthropological, archaeological, odontological, genetic, forensic investigations.

Canines differ from other teeth with respect to survival and sex dichotomy and are supported by their high level of survival in the dentition. The mandibular canines are not only exposed to less plaque, calculus, abrasion from brushing, or heavy occlusal loading than other teeth, they are also less severely affected by periodontal disease and so, usually are the last teeth to be extracted with respect to age. These findings indicate that mandibular canines can be considered as the "key teeth" for personal identification [38].

Mandibular canines are found to exhibit the greatest sexual dimorphism among all teeth [9]. The notable difference between canine in determining sex was noted to be due to the influence of the $\mathrm{Y}$ chromosome which was not uniform in all teeth. On the other hand, the $\mathrm{X}^{-}$linked genetic influence on tooth width was rather uniform for all teeth [11].

Sexual Dimorphism refers to differences in size, stature and appearance between male and female [39]. In the field of forensic odontology, permanent canine teeth and their arch width (distance between the canine tips) have been reported to show sexual dimorphism [40]. Sex determination using dental characteristics is based on the comparison of tooth size between male and female [41] or the frequency of characteristic evolutionary morphological features, such as the presence of the cusp of Carabelli on the maxillary molars. The two most commonly used odontometric parameters in determining a person's sex based on dental measurements are the mesiodistal and bucco-lingual crown diameter of the permanent teeth [42]. The mesiodistal diameter of the maxillary and mandibular canines provides evidence of sex determination based on the existence of sexual dimorphism [43]. In our study we considered mandibular canines and elucidated the role of canine indices of right and left mandibular canine in sex determination including the sexual dimorphism in both the canines which showed statistically significant results. We also attempted to compare the percentage accuracy of gender determination of our study with those done by various authors (Table 8).

It is concluded that the mesiodistal widths of mandibular canines and inter-canine widths are significantly different in males and females, as are the mandibular canine indices. 
Table 8. Comparing Percentage Accuracy of Gender Determination with Various Similar Studies.

\begin{tabular}{|c|c|c|c|c|}
\hline Author & Region & $\begin{array}{c}\text { Percentage } \\
\text { Accuracy in } \\
\text { Predicting } \\
\text { Males }\end{array}$ & $\begin{array}{c}\text { Percentage } \\
\text { Accuracy in } \\
\text { Predicting } \\
\text { Females }\end{array}$ & $\begin{array}{c}\text { Total } \\
\text { Percentage } \\
\text { Accuracy }\end{array}$ \\
\hline Present study & Telangana & $73.3 \%$ & $70 \%$ & $71.7 \%$ \\
\hline Geeta et al. [44] & Telangana & $80 \%$ & $76.66 \%$ & $78.3 \%$ \\
\hline Acharya \& Mainali [45] & Karnataka & $57.14 \%$ & $44.44 \%$ & $51.28 \%$ \\
\hline Rao et al. [11] & Karnataka & $84.3 \%$ & $87.5 \%$ & $85.9 \%$ \\
\hline Reddy et al. [14] & Uttar Pradesh & $78 \%$ & $66 \%$ & $72 \%$ \\
\hline Dhara Parekh [46] & Gujarat & $50.5 \%$ & $55.3 \%$ & $52.4 \%$ \\
\hline Ahmed [47] & Iraq & $32 \%$ & $59 \%$ & $45.5 \%$ \\
\hline Kakkar et al. [48] & Punjab & $53.54 \%$ & $55.03 \%$ & $54.44 \%$ \\
\hline Narang S et al. [38] & Punjab & $68 \%$ & $67.6 \%$ & $67.8 \%$ \\
\hline
\end{tabular}

The right mandibular canine was found to be more dimorphic than left mandibular canine. The parameters measured in the present study will be of immense help in identification of sex in forensic investigations.

Kaushal et al in their study on North Indian population have concluded that the probability of sex determination using right MCI for males and females is $70 \%$ and $80 \%$ respectively and that with left MCI for males and females has been $66.67 \%$ and $83.33 \%$ respectively. This is in contrast to our findings which showed $73.3 \%$ in males and $70.0 \%$ in females using MCI of right side and $66.7 \%$ males and $56.7 \%$ females using MCI of left side [15].

Further, the probability of correct prediction of sex using MCI is higher for males in our study which was in agreement with the study conducted by Fouad Ayoub et al. [4449] on Lebanese population showed the probability of male sex determination to an extent as high as $95 \%$ having the width of either canine greater than $7.104 \mathrm{~mm}$ in its dimensions We have noted an overall higher percentage of accuracy for sex prediction from right side MCI as compared to left side. It is also concluded that a canine width greater than $7.3 \mathrm{~mm}$ is $100 \%$ suggestive of males.

From the findings of this study and those done on other populations, the mandibular canine width and inter-canine distance have indeed proven beyond doubt high degree of sexual dimorphism, hence can be used as a useful material in forensic identification as an adjunct tool along with other procedures for the determination of sex in cases of highly mutilated and damaged bodies where jaws are at hand. Variations in the intensity of sexual dimorphism and percentage accuracy of sex determination in different studies and different populations may be explained by genetics, the influence of environmental factors, different eating habits and the complex coordinated action of environmental factors and biological influences [50]. Thus these findings support the usefulness of employing odontometric analysis of the canine teeth in gender determination as an easy, reproducible and objective method.

\section{CONCLUSION}

Forensic identification of living or deceased though is a tedious job but is a comprehensive work involving the coordinated efforts of multidisciplinary team employing different techniques in the face of which it also involves various other accessory methods like cheiloscopy, palatoscopy, odontometry which are unique and show individual variations. Although there are many research studies on the above three methods, the study comparing the three methods together with respect to reliability in sex discrimination is minimal. Our attempt of conducting this study gave a comparatively reliable significance of each method albeit large scale study is required in order to validate or substantiate our results to arrive at a definitive results and values. However the present study proves that the lip prints, rugae patterns and odontometric measurements have the potential in human identification where lip prints are more reliable in gender determination when compared to palatal rugae with the mandibular canine odontometrics also sharing an equal role in meeting the objective of this study on par with them. Hence all the above three methods of sex identification holds importance as an ancilliary and supplemental tools of forensic investigations.

\section{CONFLICT OF INTEREST}

The authors confirm that this article content has no conflicts of interest.

\section{ACKNOWLEDGEMENTS}

Declared none. 


\section{REFERENCES}

[1] Caldas IM, Magalhaes T, Afonso A. Establishing identity using cheiloscopy and palatoscopy. Forensic Sci Int 2007; 165: 1-9.

[2] Lampe H, Roetzscher K. Forensic Odontology: age determination from adult human teeth. Med Law 1994; 13(7-8): 623-8.

[3] Segui MA, Feucht MM, Ponce AC, Pascual F. Persistent lipsticks and their lip prints: New hidden evidence at the crime scene. Forensic Sci Int 2000; 112: 41-7.

[4] Sivapathasundharam B, Prakash PA, Sivakumar G. Cheiloscopy. Indian J Dent Res 2001; 12: 234-7.

[5] Prabhu RV, Dinkar AD, Prabhu VD, Rao PK. Cheiloscopy: Revisited. J Forensic Dent Sci 2012; 4:47-52.

[6] Saraf A, Bedia S, Indurkar A, Degwekar S, Bhowate R. Rugae patterns as an adjunct to sex differentiation in forensic identification. J Forensic Odontostomatol 2011; 29:14-9.

[7] Bakkannavar SM, Monteiro FNP, Arun M, Kumar GP. Mesiodistal width of canines: a tool for sex determination. Med Sci Law 2012; 52(1): 22-6.

[8] Kapila R, Nagesh KS, Iyengar RA, and Mehkri S. Sexual dimorphism in human mandibular canines: a radiomorphometric study in South Indian population. J Dental Res Dental Clin Dental Prospects 2011; 5(2): 51-4.

[9] Tsuchihashi Y. Studies on personal identification by means of lip prints. Forensic Sci 1974; 3: 233-48.

[10] Lysell L. Plicae palatinae transversae and papilla incisive in man: A morphologic and genetic study. Acta Odont Scand 1955; 13: 1137.

[11] Rao NG, Rao NN, Pai ML, Kotian MS. Mandibular canine index A clue for establishing sex identity. Forensic Sci Int 1989; 42: 24954

[12] Garn SM, Lewis AB. Bucco-Lingual size asymmetry and its developmental meaning. Angle Orthod 1967;37(1): 186-93.

[13] Kaushal S, Patnaik VVG, Agnihotri G. Mandibular Canines in sex determination. J Anat Soc India 2003; 52 (2): 119-24.

[14] Reddy MV., Saxena S, Bansal P. Mandibular canine index as a sex determinant: a study on the population of Western Uttar Pradesh. J Oral Maxillofac Pathol 2008; 12 (2): 56-9.

[15] Kaushal S, Patnaik VVG, Sood V, Agnihotri G. Sex determination in North Indians using Mandibular canine index. J Indian Acad For Med 2004; 26(2): 45-9.

[16] Abdullah MA. A cross sectional study of canine tooth dimorphism in establishing sex identity: A comparison of two different populations. Cairo Dental J 1998; 14(2): 191-6.

[17] Jones DG. Odontology often is final piece to grim puzzle. J Calif Dent Assoc 1998; 26: 650-1.

[18] Brannon RB, Kessler HP. Problems in mass disaster dental identification: a retrospective review. J Forensic Sci 1999; 44: 123-7.

[19] Schwartz TR, Schwartz EA, Mieszerski L, McNally L, Kobilinsky L. Characterization of deoxyribonucleic acid (DNA) obtained from teeth subjected to various environmental conditions. J Forensic Sci 1991; 36: 979-90

[20] Indira AP, Gupta M, David MP. Palatal rugae patterns for establishing Individuality. J Forensic Dental Sci 2012; 4 (1): 2-5.

[21] Gupta S, Gupta K, Gupta OP. A study of morphological patterns of lip prints in relation to gender of North Indian population. J OralBiol Craniofac Res 2011; 1: 12-6.

[22] Saraswathi TR, Mishra G, Raganthan K. Study of lip prints. J Forensic Dent Sci 2009; 1: 28-31.

[23] Naik KS, Prabhu A, Nargund R. Forensic odontology: cheiloscopy. Hong Kong Dent J 2011; 8: 25-28.

[24] Vahanwala SP, Parekh BK. Study of lip prints as an aid to forensic methodology. J Ind Dent Assoc 2000; 71: 16-19.

[25] Castello A, Alvarez M, Verdu F. Just lip prints? No: there could be something else. FASEB J 2004; 18(6): 615-6.

[26] Rohit M, Sumit G. Cheiloscopy: A Deterministic Aid for Forensic Sex Determination. J Ind Acad Oral Med Radiol 2011; 23: 17-9.
Sharma P, Saxena S, Rathod V. Comparative reliability of cheiloscopy and palatoscopy in human identification. Ind J Dent Res 2009; 20: 453-7.

[28] Harpreet S, Pankaj C, Rituha. Lip prints as evidence. J Punjab Acad Forensic Med Toxicol 2011; 11: 23-5.

[29] Dongarwar GR, Bhowate RR, Degwekar SS. Cheiloscopy-Method of person identification and sex determination. OA Sci Rep 2013; 2(1): 1-4.

[30] Rai B, Anand SC. Palatal rugae: In forensic examination. Ind Int J Forensic Med Toxicol 2007; 5: 14-6.

[31] Gondivkar SM, Patel S, Gadbail AR, Gaikwad RN, Chole R, Parikh RV. Morphological study of the palatal rugae in westernIndian population. J Forensic Leg Med 2011; 18: 310-12.

[32] Venegas VH, Valenzuela JS, López MC, Galdames IC. Palatal rugae: Systematic analysis of its shape and dimensions for use in humanidentification. Int J Morphol 2009; 27: 819-25.

[33] Bharath ST. Sex determination by discriminant function analysis of palatal rugae from a population of coastal Andhra. J Forensic Dent Sci 2011; 3: 58-62.

[34] Byatnal A, Byatnal A, Kiran AR, Samata Y, Guruprasad Y, Telagi N. Palatoscopy: An adjunct to forensic odontology: A comparative study among five different populations of India. J Nat Sci Biol Med 2014; 5(1): 52-5.

[35] Nayak P, Acharya AB, Padmini AT, Kaveri H. Diff erences in the palatal rugae shape in two populations of India. Arch Oral Biol 2007; 52: 977-82.

[36] Shetty D, Juneja A, Jain A, et al. Assessment of palatal rugae pattern and their reproducibility for application in forensic analysis. J Forensic Dental Sci 2013; 5(2): 106-9.

[37] Bansode SC, Kulkarni MM. Importance of palatal rugae in individual identification. J Forensic Dent Sci 2009; 1: 77-81.

[38] Narang RS, Manchanda AS, Malhotra R, Bhatia HS. Sex determination by mandibular canine index and molar odontometrics: A comparative study. Ind J Oral Sci 2014; 5(1): 16-20.

[39] Ghose LJ, Baghdady VS. Analysis of the Iraqi dentition: mesiodistal crown diameters of permanent teeth. J Dent Res 1979; 58: $1047-$ 54

[40] Garn SM, Lewis AB, Kerewsky RS. The relationship between sexual dimorphism in tooth size and body size as studied within families. Arch Oral Biol 1967; 12: 299-301.

[41] Vodanovic M, Demo Y, Njemirovskij V, Keros J, Brkic H. Odontometrics: a useful method for sex determination in an archeological skeletal population? J Arch Sci 2007; 37: 905-13.

[42] Iscan MY, Kedici SP. Sexual variation in buccolingual dimensions in Turkish dentition. Forensic Sci Int 2003; 137: 160-4.

[43] Mohammed QAR, Abdullah MA, Ashraf I, Khan N. Dimorphism of mandibular and maxillary canine teeth in establishing identity. SDJ 1997; 9: 17-20.

[44] Paramkusam G, Nadendla LK, Devulapalli RV, Pokala A. Morphometric analysis of canine in gender determination: Revisited in India. Ind J Dental Res 2014; 25(4): 425-9.

[45] Acharya AB, Mainali S. Limitations of the mandibular canine index in sex assessment. J Forensic Leg Med 2009; 16: 67-9.

[46] Parekh D, Zalawadia A, Ruparelia S, Patel S, Rathod SP, Patel SV. Study of Mandibular Canine Teeth Dimorphism In Establishing Sex Identity In Gujarat Region. Nat J Integr Res Med 2011; 2(2): 6-9.

[47] Ali Ahmed HM. Genders identification using mandibular canines (Iraqi study). J Bagh Coll Dentistry 2014; 26(1): 150-3.

[48] Kakkar T, Sandhu JS, Sandhu SV, Sekhon AK, Singla K, Bector K. Study of mandibular canine index as a sex predictor in a Punjabi population. Ind J Oral Sci 2013; 4(1): 23-6.

[49] Ayoub F, Shamseddine L, Rifai M, Cassia A, Diab R, Zaarour I. Mandibular Canine Dimorphism in Establishing Sex Identity in the Lebanese Population. Int J Dentistry 2014; 1: 1-4.

[50] Reddy LVK. Lip prints: An overview in Forensic Dentistry. J Adv Dent Res 2011; 2: 17-20.

(C) Nagalaxmi et al.; Licensee Bentham Open.

This is an open access article licensed under the terms of the Creative Commons Attribution Non-Commercial License (http://creativecommons.org/licenses/by-nc/3.0/) which permits unrestricted, non-commercial use, distribution and reproduction in any medium, provided the work is properly cited. 